Achim Schröter', Ferdinand Schwarzfischer², Corrado Grassi³, Yves-Simon Gloy', Burkhard Corves², Thomas Gries 'RWTH Aachen University, Faculty of Mechanical Engineering, ITA - Institüt für Textiltechnik,

Otto-Blumenthal Straße 1, 52074 Aachen, Germany

${ }^{2}$ RWTH Aachen University, Faculty of Mechanical Engineering, IGM - Department of Mechanism Theory and

Dynamics of Machines, Kackertstraße 16-18, 52072 Aachen, Germany

3ITA Technologietransfer GmbH, Otto-Blumenthal Straße 1, 52074 Aachen, Germany

\title{
Analysis of the Weft Insertion Process and Development of a Relay Nozzle Concept for Air-Jet Weaving
}

\author{
Original Scientific Article
}

Received 03-2016 • Accepted 04-2016

\begin{abstract}
Air jet weaving is the most productive method for the production of fabrics. However, the energy consumption of air jet weaving machines is significantly higher than the consumption of other weaving machines. Almost $80 \%$ of the energy consumed can be attributed to the losses at the relay nozzles. At the Institut für Textiltechnik of RWTH Aachen University, Aachen, Germany different novel relay nozzle geometries with lower air consumption have been developed on the basis of simulations and trials. The simulations have shown potential energy savings up to $50 \%$ compared to conventional relay nozzles. Furthermore, practical validations of the results of these simulations have been done. The velocity, stagnation pressure and volume flow were measured in the reed channel. In addition, an energetic and economic evaluation of the best relay nozzle geometry was done. The evaluations have shown that up to $50 \%$ of the energy can be saved.

Keywords: energy efficiency, air jet weaving, relay nozzles, energy reduction, energy savings
\end{abstract}

\section{Introduction}

\subsection{Air Jet Weaving}

The textile industry is an energy intensive industry. The increasing energy costs represent a challenge for textile manufacturers as well as for the developers of textile production machines. As example, the air jet weaving is the most productive but also the most energy consuming weaving method [1]. In the air jet weaving process the weft yarn is inserted into the shed with compressed air by using different types of nozzles. Figure 1 shows a schematic view of the weft insertion components.

The current state-of-the-art air jet weaving machines employ a tandem and main nozzle combination for the purpose to provide the initial acceleration to the weft yarn, and a series of relay nozzles along the reed channel to keep constant yarn velocity of about 55$80 \mathrm{~m} / \mathrm{s}$. A profiled reed provides guidance for the air. At the end of the insertion process a nozzle catches and stretches the yarn at the right side of the machine. A cutter is used to cut the yarn when the insertion is completed, and the beat-up movement completes the fabric production process [3].

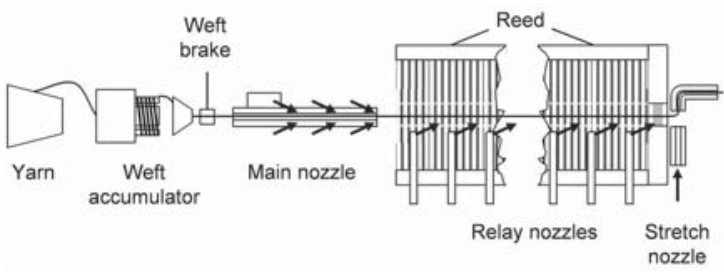

Figure 1: Schematic view of an air jet weft insertion system [2]

\subsection{Influence of the Energy Consumption}

The air-jet weaving machine combines high performance (Table 1) with low wear, because no mechanical parts are directly involved in the weft insertion process [3].

However, the main drawback regarding this technology is a very high energy consumption (Table 1) due to the compressed air usage which is required during the weft insertion process. Since the cost of energy has a systematic increasing trend, power

Tekstilec, 2016, 59(2), 182-185

DOI: 10.14502/Tekstilec2016.59.182-185 
consumption is still a challenging issue. In particular it is a limiting factor of the air jet weaving technology in the countries with high energy and manufacturing costs. An overview of the manufacturing costs of a woven fabric can be seen in Table 2 [5].

Table 1: General characteristics of air-jet weaving machine [3, 4]

\begin{tabular}{|l|c|}
\hline \multicolumn{2}{|c|}{ Air jet weaving machine } \\
\hline Weft insertion rate & $2000 \mathrm{~m} / \mathrm{min}$ \\
\hline $\begin{array}{l}\text { Average specific energy } \\
\text { consumption of woven fabric }\end{array}$ & $3-5 \mathrm{kWh} / \mathrm{kg}$ \\
\hline
\end{tabular}

For instance, in Italy the total manufacturing costs are $0.665 \mathrm{USD} / \mathrm{m}$ of woven fabric and power costs correspond to $23 \%(0.56 \mathrm{USD} / \mathrm{m})$. In other countries such as India and China, the total manufacturing costs are lower, $0.235 \mathrm{USD} / \mathrm{m}$ and $0.274 \mathrm{USD} / \mathrm{m}$ respectively, but on the other hand the power consumption is responsible for $27 \%(0.064 \mathrm{USD} / \mathrm{m})$ and $34 \%(0.092 \mathrm{USD} / \mathrm{m})$ respectively of the entire value. In order to decrease the energy consumption and to increase the energy efficiency, air-jet weaving machines are under constant development. At the Institut für Textiltechnik of RWTH Aachen University (ITA), Aachen, Germany, a novel method based on energy balances has been applied for the purpose of reducing the power costs while keeping constant the fabric quality. The study focused on the air flow field of the relay nozzles [6].

\section{Methods}

The results of the research led to the development of a new geometry of the relay nozzle which is able to provide the same value of propulsive force to the weft yarn at a lower operating pressure level. This new concept enables that the relay nozzle works at 2 bar inlet overpressure in place of 5 bar as the relay nozzles available on the market [5]. In such a way, the productivity is kept constant and the costs associated with compressors to pump up the air are decreased.

The force on the yarn in the reed channel is provided by the friction between the air and the yarn surface and is given by the following Equation 1 [7]:

$F_{W}=\frac{\rho}{2}=c_{w} A\left(c-c_{F}\right)^{2}$

The parameter $A$ is the yarn surface, $\rho$ is the air density and $c_{w}$ is the skin friction coefficient.

The force is proportional to the square of the relative velocity between the air stream $c$ and the yarn $c_{F}$. So the air velocity is one of the most important influences on the propelling force.

Assumptions for the further hypothesis:

- steady state flow

- negligible yarn flexibility

- constant yarn velocity across the shed

- lossless flow

- no shockwaves

- no change of flow direction

- round free stream.

The thrust provided by the relay nozzles to the yarn has the highest influence on the productivity of the machine and on the quality of the product.

The study carried out at ITA focused on the development of a new geometry of the nozzle in order to reduce the acting pressure without negatively affecting the productivity. Therefore, an analytical mathematical model was set up at ITA which calculates the maximum velocity along the free stream of an ideal nozzle. This calculation should help to estimate the amount of air velocity a nozzle is able to

Table 2: Overview of the manufacturing costs of a woven fabric in USD per meter [5]

\begin{tabular}{|l|c|c|c|c|c|c|c|c|}
\hline & Brazil & China & Egypt & India & Italy & Korea & Turkey & USA \\
\hline Waste & 0.006 & 0.008 & 0.007 & 0.005 & 0.008 & 0.006 & 0.006 & 0.006 \\
\hline Labour & 0.047 & 0.036 & 0.016 & 0.009 & 0.244 & 0.120 & 0.053 & 0.146 \\
\hline Power & 0.085 & 0.092 & 0.028 & 0.064 & 0.156 & 0.064 & 0.057 & 0.036 \\
\hline Auxiliary material & 0.037 & 0.042 & 0.05 & 0.048 & 0.094 & 0.054 & 0.059 & 0.033 \\
\hline Depreciation & 0.077 & 0.072 & 0.058 & 0.065 & 0.132 & 0.064 & 0.062 & 0.099 \\
\hline Interest & 0.06 & 0.024 & 0.039 & 0.044 & 0.031 & 0.018 & 0.031 & 0.022 \\
\hline $\begin{array}{l}\text { Total manufacturing } \\
\text { costs [USD/m] }\end{array}$ & 0.312 & 0.274 & 0.198 & 0.235 & 0.665 & 0.326 & 0.268 & 0.342 \\
\hline
\end{tabular}


reach under ideal circumstances. This calculation helps to benchmark the new designed nozzle.

The mathematical model calculates the flow parameters under ideal conditions and is shown in Equation 2:

$c\left(r_{F}, d, x, c_{0}\right)=c_{0} \frac{d}{d+m x} \exp \left(-\frac{r_{F}^{2}}{m(d+m x)}\right)$

The parameter $c_{0}$ is the air velocity in the core zone and $d$ is the diameter of the nozzle. The parameter $m$ describes the mixing factor. The position of the yarn is given by the parameter $r_{F}$ and the position $x$. The parameters are shown in Figure 2.

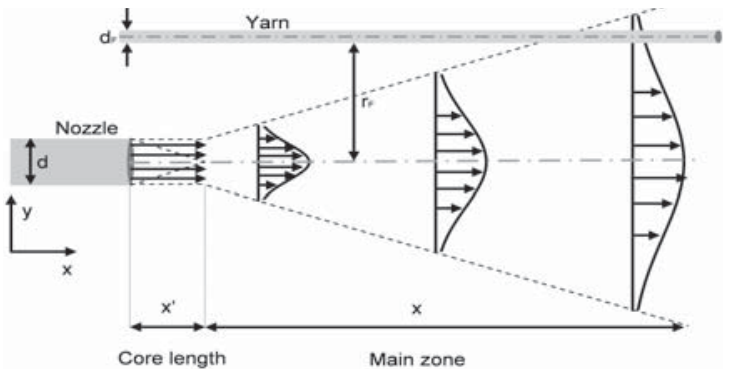

Figure 2: Schematic view of a free stream and the position of the yarn

\section{Results}

By comparing the nozzle design with the mathematical model, different flow simulations have been carried out. The simulations are done by using the Computational Fluid Dynamics (CFD) simulation tool ANSYS Fluent from ANSYS, Inc., Canonsburg, USA. The simulation is based on the following assumptions: compressible flow field, ideal gas, steady state flow.

Based on these assumptions a CFD model was set up and a CAD-model was integrated into this model. Behind the nozzle outlet a free flow field with ambient pressure is modulated. At the inlet of the nozzle, 1 bar overpressure was set as a condition. The CFD model with the simulated flow field is shown in Figure 3.

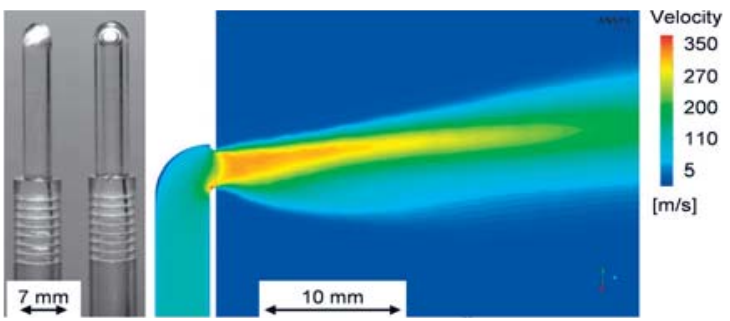

Figure 3: Simulated flow field of the new nozzle concept

The air stream out of the nozzle is very compact (e.g. low divergence flow, no shock waves) and has a small blowing angle of $6-8^{\circ}$. In Figure 4 the simulated velocity of the air stream up to a distance of $120 \mathrm{~mm}$ behind the nozzle is shown and compared to the analytical model. Figure 4 shows the velocity of the air on the vertical axes, and the distance downstream the nozzle on the horizontal axes. The nozzle is located in the origin.

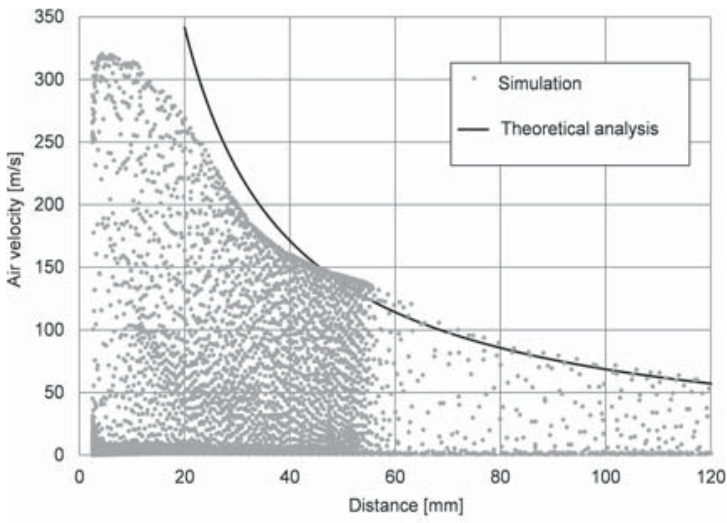

Figure 4: Comparison between the velocity of the simulated air stream of the nozzle and the ideal analytical model

It can be seen that the velocity of the air is higher than the velocity of $50 \mathrm{~m} / \mathrm{s}$ for a distance of around $120 \mathrm{~mm}$ in the simulation and the theoretical model. The flow of the nozzle is guided and, therefore, the developed nozzle works effectively. The difference between the simulation and the theoretical model is resulting from the condition that the model calculates with a lossless nozzle without change of the flow direction.

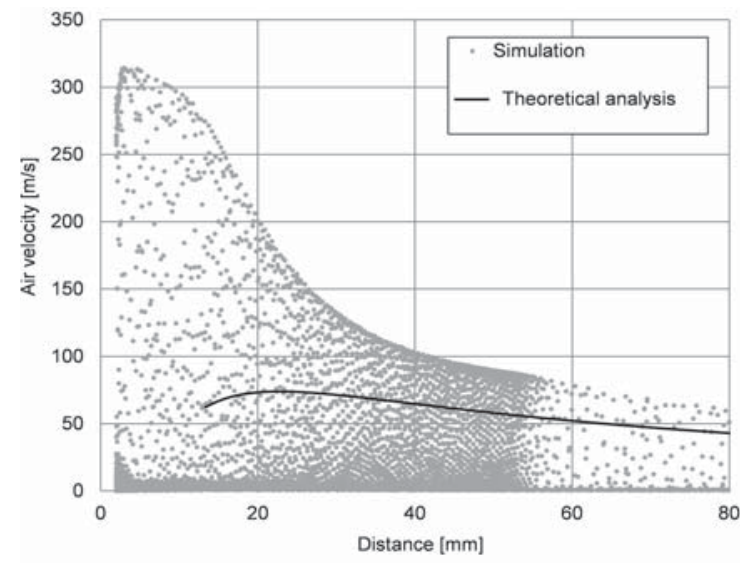

Figure 5: Comparison between the simulated air stream of the nozzle and the calculated flow in the free stream at the position of the yarn 
The simulation cannot give any information about the flow condition inside the reed without raising the simulation time. Because of the two-dimensional projection of the analytical model, the calculation of the flow field at the position of the yarn in the free stream is possible. This calculation gives an estimation of the flow field which is affecting the yarn. Figure 5 shows the calculated flow field at the position of the yarn compared with the simulation in the central layer of the nozzle.

At a distance of $50 \mathrm{~mm}$ the velocity of the flow field goes under a value of $50 \mathrm{~m} / \mathrm{s}$ (see Figure 5). Despite of the lower reachable distance the energy saving potential of the nozzle is about $50 \%$, due to the low operating pressure of 1 bar. Measurements in the reed channel show similar results compared to the analytical model. Only the distance behind the nozzle is different. This difference can be explained by the influence of the reed which is not considered in calculation. Indeed, this difference has no effect on the energy balance of the weaving machine.

\section{Conclusion}

At the Institut für Textiltechnik of RWTH Aachen University, Aachen, Germany, a novel method has been developed to identify potentials for saving energy during textile production processes [1]. The air-jet weaving process is the most productive but also the most energy intensive weaving process. The pneumatic components of the machine have been identified as the biggest energy consumer. Based on a theoretical model of the weft insertion, a new concept of the relay nozzle has been drawn. By means of CFD simulations, the potential of the nozzle is shown which enables the energy reduction up to $50 \%$. Nevertheless, the simulation includes a faithful reproduction of the free flow field of the relay nozzle, without taking into account the interaction with the profiled reed and, therefore, it gives a first insight on how to reduce the power consumption of the weft insertion process. The simulations were validated by a theoretical model and the measurement of the air velocity.

\section{Acknowledgments}

The VIP0477 project is in the form of assistance "Validierung des innovationpotenzials wissenschaftlicher Forschung - VIP" supported by the German Federal Ministry for Education and Research (BMBF).
The European Commission is gratefully acknowledged for its support of the Marie Curie program through ITN EMVeM project, Grant Agreement No: 315967.

\section{References}

1. SCHRÖTER, Achim, HOLTERMANN, Timm, GLOY, Yves-Simon, GRIES, Thomas. Steigerung der Energieeffizienz des Luftdüsenwebverfahrens am Institut für Textiltechnik [online] [accessed 15. 3. 2016]. 14. Chemnitzer Textiltechnik Tagung : 13. und 14. Mai 2014, Chemnitz. Available on World Wide Web: <https://www. tu-chemnitz.de/mb/FoerdTech/ctt/pdf/1_5.pdf>.

2. HOLTERMANN, Timm. Methode zur Bewertung und Erhöhung der Energieeffizienz von Produktionsprozessen der Textilindustrie : Dissertation. Aachen : Shaker, 2014, 378 p.

3. ADANUR, Sabit. Handbook of weaving. Boca Raton ; London ; New York ; Washington, D.C. : CRC Press, 2001, 448 p.

4. KOÇ, Erdem, ÇİNÇİK Emel. Analysis of energy consumption in woven fabric production. Fibres and Textiles in Eastern Europe, 2010, 18,(2), $14-20$.

5. International production cost cmparison: spinning / texuring / weaving / knitting - IPCC. Press release. ITMF's international production cost comparison 2014 - spinning, texturing, weaving and knitting. ITMF International Textile Manufacturers Federation [online] [accessed 15. 3. 2016]. Available on World Wide Web: <http:// www.itmf.org/wb/pages/home/publications/ pressrelease.php?id=6>.

6. SCHRÖTER, Achim, GRASSI, Corrado. Increasing the energy efficiency of air jet weaving based on a novel method to exploit energy savings potentials in production processes of the textile industry. In: 15th Autex Conference, June 10-12, 2015, Bucharest, Romania. Edited by Mirela BLAGA. Proceedings. Iasi: "Gheorghe Asachi” Technical University, Faculty of Textiles, Leather and Industrial Management, 2015.

7. OERTEL jr, Herbert. Prandtl - Führer durch die Strömungslehre: Grundlagen und Phänomene. 13. Aufl. Wiesbaden : Springer Vieweg, 2012, 764 p., doi: 10.1007/978-3-8348-2315-1. 